\title{
Effect of Ethanol on Ketone Metabolism
}

\author{
André Lefèvre, Howard Adler, and Charles S. Lieber \\ From the Section of Liver Disease and Nutrition, Bronx VA Hospital and the \\ Department of Medicine, Mt. Sinai School of Medicine of the City University \\ of New York, New York 10468
}

A B S T RACT Ketonuria has been observed in alcoholics. To study the mechanism of this effect, healthy, volunteers were given adequate diets (36\% of calories as lipid and $15 \%$ as protein) for 18 days, with isocaloric replacement of carbohydrate ( $46 \%$ of calories) by either ethanol or additional fat. The latter resulted in a high fat diet, with $82 \%$ of calories as lipid. After about 1 wk of alcohol, massive and persistent ketonuria developed. Compared with the control period, there was a 30 -fold increase in fasting blood acetoacetate and $\beta$-hydroxybutyrate $(P<0.001)$. With the high fat diet, acetoacetate and $\beta$-hydroxybutyrate increased 8 - to 10 -fold $(P<0.001)$. In the postprandial state, ethanol also induced hyperketonemia, but less markedly than when ethanol followed an overnight fast. With low fat diets ( $5 \%$ of calories), alcohol ( $46 \%$ of total calories) did not induce ketonuria or hyperketonemia, suggesting that a combination of alcohol and dietary fat is necessary. The addition of alcohol to rat liver slices did not affect ketogenesis. In rats pretreated with alcohol for 3 days, however, ketonemia developed, hepatic glycogen was decreased, and liver slices (incubated with palmitate $-{ }^{14} \mathrm{C}$ and glucose) had a significant increase in acetoacetate production, when compared to carbohydrate pretreated controls. Alcohol pretreatment or addition of alcohol in vitro had no effect on acetoacetate utilization by rat diaphragms, and decreased only slightly the conversion of $\beta$-hydroxybutyrate $-{ }^{14} \mathrm{C}$ to ${ }^{14} \mathrm{CO}_{2}$. Thus, the hyperketonemia and ketonuria observed after alcohol consumption cannot be attributed to an immediate effect of alcohol, but is the consequence of a delayed change in intermediary metabolism characterized by increased hepatic ketone production from fatty acids, possibly linked to ethanol-induced glycogen depletion and depression of citric acid cycle activity.

Received for publication 9 October 1969 and in recised form 3 June 1970.

\section{INTRODUCTION}

Ketonuria has been reported episodically in patients with acute alcoholic intoxication but it is generally attributed to factors commonly associated with alcoholism, mainly poor nutritional status and (or) fasting (1).

The frequent occurrence, however, of ketonuria in our patients receiving alcohol ${ }^{1}$ with an adequate diet suggested that alcohol per se may play a role. This prompted us to investigate ketonemia and ketonuria after administration of alcohol under controlled conditions, in order to study its pathogenesis, especially the respective roles of ethanol and dietary factors.

\section{METHODS}

\section{Clinical studies}

Subjects. Nine volunteers were studied under metabolic ward conditions. All but two were males and their ages varied from 35 to $58 \mathrm{yr}$. All had a history of alcoholism but, at the time of the study, they had abstained from alcohol for periods of 3-10 wk and none had clinical evidence of liver disease. Liver biopsy done during the control period revealed normal morphology in every subject. Liver function tests including BSP, bilirubin, SGOT, albumin, total protein, and prothrombin time were all normal.

Diets and procedures. The composition of the various diets is indicated in Fig. 1. All the diets had an adequate content of nutrients, including amounts of protein, vitamins, and minerals above the daily recommended allowances (2), and were given equally in three daily feedings. Special care was given to the maintenance of total food intake both during the control and ethanol periods. Total caloric intake varied between 2100 and 2620 cal according to the subject and the individuals maintained stable body weight within $3 \%$ of the control period during the entire study.

After control periods of at least 10 days, alcohol or fat was isocalorically substituted for carbohydrate for periods varying from 17 to 51 days. Alcohol, considered to have a caloric value of $7 \mathrm{cal} / \mathrm{g}$, was administered (divided in seven daily doses) equally at $2 \frac{1}{2}-\mathrm{hr}$ intervals between 7 a.m. and 10 p.m. as flavored diluted ethanol. Even with the highest dosage,

\footnotetext{
${ }^{1}$ The terms alcohol and ethanol (ethyl alcohol) are used interchangeably in this paper.
} 


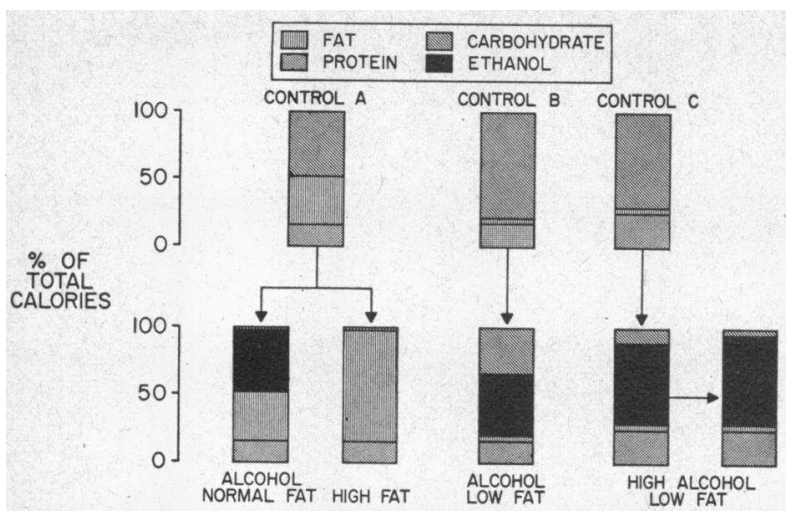

FIgURE 1 Composition of the various diets and sequence in which they were given.

alcohol produced only mild euphoria without gross intoxication.

Three subjects received the control diet A (balanced diet) and the corresponding experimental diets illustrated in Fig. 1 ; two individuals were given the control diet B (low fathigh carbohydrate diet) and the corresponding alcohol diet, while one subject remained on the metabolic ward long enough to receive the two control diets $\mathrm{A}$ and $\mathrm{B}$ and their corresponding experimental diets. Three other individuals were given the control diet $\mathrm{C}$ similar to diet $\mathrm{B}$ except for a higher protein content ( $25 \%$ of total calories). In these studies, carbohydrate was replaced by ethanol up to $60 \%$ of total calories; in one of these three subjects, the alcohol dose was increased up to $66 \%$ of total calories, with only $4 \%$ of total calories remaining as carbohydrate.

Chemical assays. Blood samples were collected twice a week in the morning (in the fasting state) before alcohol administration, and twice a week in the afternoon, $3 \mathrm{hr}$ after lunch (and $90 \mathrm{~min}$ after the afternoon alcohol dose).

Blood was immediately cooled in ice water; in some aliquots proteins were rapidly precipitated according to Weichselbaum and Somogyi (3) and supernatants were frozen at $-20^{\circ} \mathrm{C}$ until analysis; other aliquots were centrifuged and plasma or serum were also frozen. Acetoacetate was determined by the method of Walker (4), $\beta$-hydroxybutyrate according to Michaels, Margen, Liebert, and Kinsell (5), and serum alcohol by the method of Bonnichsen (6). The acetoacetate determinations were always performed no more than 60 days after blood samples were taken; in our storage conditions the spontaneous decarboxylation of acetoacetate in frozen filtrates $\left(-20^{\circ} \mathrm{C}\right)$ was found to be less than $5 \%$, with absolute values in the same order of magnitude as reported by Walker (4). 24-hr urine collections were stored in the cold $\left(4^{\circ} \mathrm{C}\right)$, with toluol as preservative. Aliquots were treated by the Somogyi procedure (3) and acetoacetate (4) and $\beta$-hydroxybutyrate (5) concentrations were measured.

\section{Animal studies}

Male rats, purchased as groups of litter mates and weighing from 140 to $220 \mathrm{~g}$, were housed in individual wired bottom cages and pair fed liquid diets as described previously (7) ; the diets contained carbohydrates or an isocaloric amount of alcohol introduced gradually; $30 \mathrm{~g} /$ liter the 1st day, $40 \mathrm{~g} /$ liter the $2 \mathrm{nd}$ day, and $50 \mathrm{~g} /$ liter the $3 \mathrm{rd}$ day (cor- responding to $36 \%$ of total calories). In one set of experiments, rats were given the liquid diets intragastrically (6 $\mathrm{ml} / 100 \mathrm{~g}$ body weight, containing either $3 \mathrm{~g} / \mathrm{kg}$ of alcohol or an isocaloric amount of carbohydrate) at the end of the 3rd day. They were then fasted overnight and sacrificed in the early morning of the 4th day. In a second set of experiments, rats were fed until the morning of the 4th day of the experiment. They were then given intragastrically $5 \mathrm{ml}$ of the diets per $100 \mathrm{~g}$ of rat body weight and were sacrificed $2 \frac{1}{2} \mathrm{hr}$ later. A third group of rats were fed Purina Chow until the day before sacrifice; they were then given intragastrically $6 \mathrm{ml}$ of diet per $100 \mathrm{~g}$ body weight and were killed $15 \mathrm{hr}$ later after an overnight fast. Blood alcohol levels in other similarly treated rats have been measured and were $0,100-125 \mathrm{mg} / 100 \mathrm{ml}$, and 0 , respectively, in each group.

All animals were sacrificed by decapitation. Diaphragm incubation experiments were performed only in fed rats while liver incubation experiments were done for each of the three groups of rats described above. Diaphragms were quickly removed and cut medially. Each half-diaphragm was placed in Erlenmeyer flasks with $3 \mathrm{ml}$ of Krebs' bicarbonate medium, slightly modified according to Beatty et al. (8) and containing acetoacetate at a concentration of $0.5 \mu \mathrm{mole} / \mathrm{ml}$ and potassium DL- $\beta$-hydroxybutyrate $-3-{ }^{14} \mathrm{C}^{2}$ at a concentration of $2 \mu \mathrm{moles} / \mathrm{ml}(0.5 \mu \mathrm{Ci} / \mathrm{ml})$. In some experiments, ethanol or sodium acetate were added at a concentration of $10 \mu$ moles $/ \mathrm{ml}$. The flasks were gassed with a mixture of $\mathrm{O}_{2}$ (95\%) and $\mathrm{CO}_{2}(5 \%)$ for $5 \mathrm{~min}$ and then shaken in a Dubnoff water bath at $37^{\circ} \mathrm{C}$ for $2 \mathrm{hr}$. The incubation was stopped by the addition of $0.2 \mathrm{ml}$ of $10 \mathrm{~N}$ sulfuric acid and the $\mathrm{CO}_{2}$ released was collected in $1 \mathrm{ml}$ of $0.5 \mathrm{M}$ Hyamine introduced in the center well. An aliquot of Hyamine was dissolved in toluene containing PPO ( $4 \mathrm{~g} /$ liter $)$ and POPOP (50 mg/liter) (9) and counted in a liquid scintillation counter. Suitable corrections were made for background and quenching. The medium was neutralized with concentrated $\mathrm{KOH}$, the protein was precipitated by the Somogyi procedure, and supernatant was frozen until acetoacetate was measured as described above. Correction was made for spontaneous degradation of acetoacetate during the procedure by measuring the disappearance of acetoacetate in control flasks containing no diaphragm but handled in a similar fashion.

The liver was quickly removed after sacrifice of the rat and slices were prepared in the cold with a Stadie-Riggs slicer, as described previously (10); they were then randomly distributed in flasks containing $5 \mathrm{ml}$ isotonic Krebs-Ringer bicarbonate buffer, $\mathrm{pH} 7.4$, with albumin $(4 \mathrm{~g} / 100 \mathrm{ml})$, palmitate- $1-{ }^{14} \mathrm{C}^{2}$ at a concentration of $0.5 \mu \mathrm{mole} / \mathrm{ml}(0.3-0.5$ $\mu \mathrm{Ci} / \mathrm{ml}$ ), and glucose $(5 \mu \mathrm{moles} / \mathrm{ml})$; ethanol was added to half of the flasks at a concentration of $10 \mu \mathrm{moles} / \mathrm{ml}$. The flasks were gassed, incubated, and the ${ }^{14} \mathrm{CO}_{2}$ determined as previously described for the diaphragms.

The final concentrations of acetoacetate were measured in aliquots of medium treated as described for the diaphragm experiments, except that the reaction was stopped with citric acid $(50 \% \mathrm{w} / \mathrm{v})$. Concomitantly, radioactivity of acetoacetate was measured in other aliquots through its decarboxylation with aniline citrate (11). For some experiments, aliquots of the liver were dropped immediately after sacrifice in hot solution of potassium hydroxide $(30 \% \mathrm{w} / \mathrm{w})$ and their glycogen concentrations were measured with the anthrone reagent according to Hassid and Abraham (12).

${ }^{2}$ Purchased from New England Nuclear, Boston, Mass. 


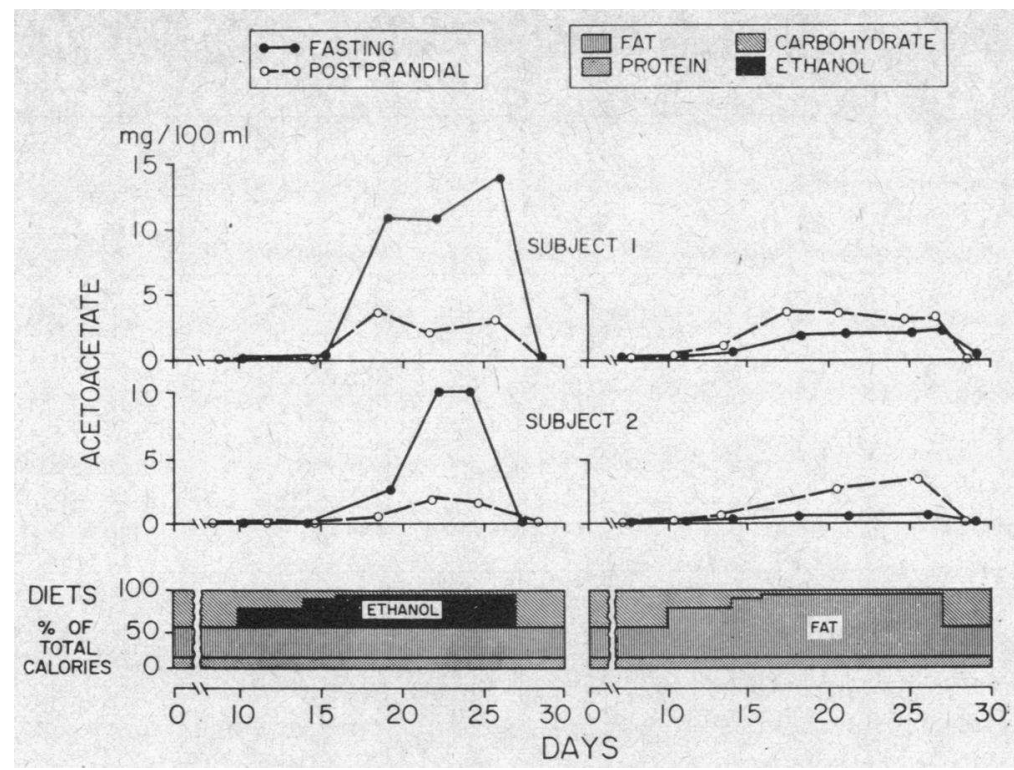

FIGURE 2 The effect of isocaloric replacement of dietary carbohydrate (by either alcohol or fat) on blood acetoacetate concentration in two subjects, both in the fasting and postprandial states.

\section{RESULTS}

Studies in man. Figs. 2 and 3 depict the acetoacetate and $\beta$-hydroxybutyrate blood levels in subjects 1 and 2 when given alcohol with a normal-fat diet or when fed the corresponding high fat diet.

In these individuals, as well as in subjects 3 and 4, replacement of dietary carbohydrate by ethanol resulted in a striking increase of the fasting levels of both ketone bodies. The peak effect was usually reached after 4-6 days of the full alcohol dose, although some differences between patients were observed. When isocaloric fat was given instead of ethanol, the effect on fasting ketone levels was much less striking. Blood ethanol levels $90 \mathrm{~min}$ after the afternoon alcohol dose did not exceed $145 \mathrm{mg} / 100 \mathrm{cc}$ and were usually much lower except in a single instance when it reached 178 $\mathrm{mg} / 100 \mathrm{cc}$. In the fasting state ethanol was not detectable in the plasma.

For the purpose of quantitative comparison of the effects of alcohol and dietary fat, data obtained during the last two-thirds of the study period (during which alcohol or fat substitution amounted to $46 \%$ of total calories) were combined, as represented in Table I. The administration of alcohol, with a normal fat-containing diet, produced a 30 -fold increase of blood $\beta$-hydroxybutyrate and acetoacetate $(P<0.001)$ in the fasting state. These increases were much more striking than those achieved with the "ketogenic" high fat diet (an 8- to 10-fold rise for $\beta$-hydroxybutyrate and acetoacetate $P<0.001$ ). The difference between the ketogenic effect of alcohol and the high fat diet was highly significant both for $\beta$-hydroxybutyrate $(P<0.001)$ and acetoacetate $(P<0.001)$.

In the postprandial state, the ketogenic effect of ethanol, though striking, was not as pronounced as after fasting: $\beta$-hydroxybutyrate increased 13 -fold after ethanol $(P<0.001)$ and 8 -fold after a high fat diet $(P<0.001)$. The difference between the ketogenic effects of ethanol and the high fat diet was not significant. The changes of acetoacetate blood levels were much less striking in the postprandial than in the fasting state and were comparable after alcohol and the high fat diet.

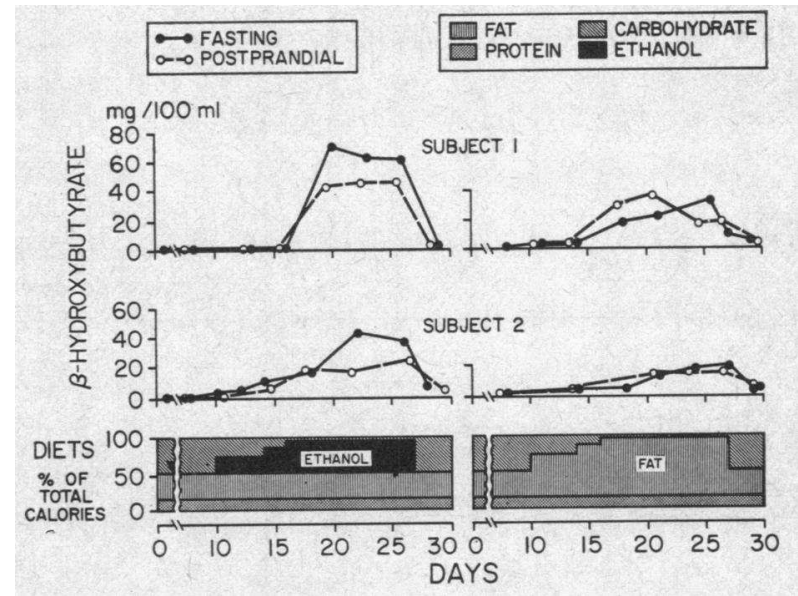

Figure 3 The effect of isocaloric replacement of dietary carbohydrate (by either alcohol or fat) on blood $\beta$-hydroxybutyrate concentration in two subjects, both in the fasting and postprandial states.

Effect of Ethanol on Ketone Metabolism 
TABLE I

Effect of Ethanol and (or) Dietary Fat on Blood Ketones $(\mathrm{mg} / 100 \mathrm{ml})$

\begin{tabular}{|c|c|c|c|c|c|c|c|c|}
\hline \multicolumn{4}{|c|}{$\begin{array}{l}\text { Diet composition } \\
\text { (\% of total calories) }\end{array}$} & \multirow{3}{*}{$\begin{array}{c}\text { No. of } \\
\text { subjects }\end{array}$} & \multirow{2}{*}{\multicolumn{2}{|c|}{$\beta$-Hydroxybutyrate }} & \multirow{2}{*}{\multicolumn{2}{|c|}{ Acetoacetate }} \\
\hline \multirow[b]{2}{*}{ Ethanol } & \multirow[b]{2}{*}{ Fat } & \multirow{2}{*}{$\begin{array}{l}\text { Carbo- } \\
\text { hydrate }\end{array}$} & \multirow[b]{2}{*}{ Protein } & & & & & \\
\hline & & & & & Fasting & Postprandial & Fasting & Postprandial \\
\hline - & 36 & 49 & 15 & 4 & $1.8 \pm 0.4$ & $2.1 \pm 0.2$ & $0.27 \pm 0.06$ & $0.26 \pm 0.05$ \\
\hline 46 & $\begin{array}{l}36 \\
82\end{array}$ & $\begin{array}{l}3 \\
3\end{array}$ & $\begin{array}{l}15 \\
15\end{array}$ & $\begin{array}{l}4 \\
4\end{array}$ & $\begin{array}{l}49.9 \pm 6.3 \\
15.8 \pm 3.0\end{array}$ & $\begin{array}{l}27.4 \pm 4.9 \\
16.2 \pm 2.1\end{array}$ & $\begin{array}{l}7.6 \pm 0.9 \\
2.2 \pm 0.5\end{array}$ & $\begin{array}{l}1.7 \pm 0.2 \\
2.3 \pm 0.3\end{array}$ \\
\hline- & 5 & $\frac{80}{70}$ & $\frac{15}{25}$ & 6 & $1.2 \pm 0.4$ & $1.7 \pm 0.6$ & $0.26 \pm 0.07$ & $0.29 \pm 0.08$ \\
\hline 46 & 5 & 34 & 15 & 3 & $2.9 \pm 0.5$ & $3.6 \pm 0.5$ & $0.27 \pm 0.07$ & $0.17 \pm 0.02$ \\
\hline 60 & 5 & 10 & 25 & 3 & $5.2 \pm 0.9$ & $4.2 \pm 0.8$ & $0.44 \pm 0.10$ & $0.29 \pm 0.12$ \\
\hline 66 & 5 & 4 & 25 & 1 & $9.5 \pm 0.5$ & $7.1 \pm 1.9$ & $1.0 \pm 0.4$ & $0.53 \pm 0.18$ \\
\hline
\end{tabular}

It should be pointed out that during the feeding of the alcohol diet the ratio of $\beta$-hydroxybutyrate over acetoacetate was doubled in the postprandial state but was normal in the fasting state when compared to the ratio observed with the high fat diet; this indicates that the modification of the redox state induced by alcohol had already regressed in the fasting state.

. The blood data were corroborated by the observation that large amounts of ketone bodies were excreted in the urines. As expected from the blood values, the daily urinary excretions of acetoacetate and $\beta$-hydroxybutyrate during the alcohol period (214 $\pm 32 \mathrm{mg}$ and $995 \pm 143$ $\mathrm{mg}$, respectively) were more pronounced than those observed during the administration of the high fat diets (116 $\pm 14 \mathrm{mg}$ and $409 \pm 49 \mathrm{mg}$ ).

When the fat content of the diet was reduced to $5 \%$ of total calories, the same amount of alcohol (46\% of total calories) did not induce any ketonuria and blood acetoacetate and $\beta$-hydroxybutyrate concentrations were not significantly different from those observed during the control periods (Table I).

In three individuals (Nos. 7, 8, and 9) who received the same low fat diet ( $5 \%$ of total calories), but with larger amounts of alcohol (60\% of total calories) for longer periods of time, alcohol substitution had no effect in one patient (No. 8) and increased the ketone blood levels very slightly in the two others, who, intermittently, presented trace amounts of ketonuria. The increase of alcohol up to $66 \%$ in one patient produced only slight ketonemia or ketonuria.

Animal studies. Table II shows that, in the fed as well as in the fasted rats, pretreatment for 3 days with an isocaloric amount of ethanol instead of carbohydrate induced a significant increase of blood acetoacetate concentration $(1.09 \pm 0.48 \mathrm{mg} / 100 \mathrm{ml}$ compared to 0.38 $\pm 0.03 \mathrm{mg} / 100 \mathrm{ml}$ in the fed rats and $3.90 \pm 0.30 \mathrm{mg} / 100$ $\mathrm{ml}$ compared to $1.70 \pm 0.20 \mathrm{mg} / 100 \mathrm{ml}$ in the fasted rats), mimicking, in rats, the findings we observed in man.

Concomitantly, the liver slices from the ethanol-pretreated rats produced significantly more acetoacetate than those of the carbohydrate-fed animals : $158 \pm 10 \mu \mathrm{g} / \mathrm{g}$ of liver per $\mathrm{hr}$ versus $107 \pm 9$ in the fed animals $(P<$ $0.001)$ and $468 \pm 49 \mu \mathrm{g} / \mathrm{g}$ of liver per hr versus $274 \pm 43$ in the fasted rats $(P<0.01)$.

TABLE II

Effect of Ethanol Pretreatment (with and without Fasting) on Ketonemia, Hepatic Ketogenesis, and Glycogen Concentration

\begin{tabular}{|c|c|c|c|c|c|}
\hline & \multirow[b]{2}{*}{ Pretreatment } & \multirow[b]{2}{*}{ Blood acetoacetate } & \multicolumn{2}{|c|}{ Liver slices } & \multirow[b]{2}{*}{ Liver glycogen } \\
\hline & & & $\begin{array}{l}\text { Acetoacetate } \\
\text { production }\end{array}$ & $\begin{array}{c}\text { Percent of } \\
\text { palmitate-14C } \\
\text { converted to } \\
\text { acetoacetate- }{ }^{-14} \mathrm{C}\end{array}$ & \\
\hline & & $\mathrm{mg} / 100 \mathrm{ml}$ & $\begin{array}{l}\mu g \text { per } g \text { of } \\
\text { liver per } h r\end{array}$ & $\%$ & $m g / g$ \\
\hline Nonfasted rats & $\begin{array}{l}\text { Control diet } \\
\text { Ethanol diet }\end{array}$ & $\begin{array}{l}0.38 \pm 0.03 \\
1.09 \pm 0.48\end{array}$ & $\begin{array}{l}107 \pm 9 \\
158 \pm 10\end{array}$ & $\begin{array}{l}0.54 \pm 0.06 \\
1.25 \pm 0.13\end{array}$ & $\begin{array}{l}37.1 \pm 4.4 \\
20.2 \pm 5.0\end{array}$ \\
\hline Fasted rats & $\begin{array}{l}\text { Control diet } \\
\text { Ethanol diet }\end{array}$ & $\begin{array}{l}1.70 \pm 0.20 \\
3.90 \pm 0.30\end{array}$ & $\begin{array}{l}274 \pm 43 \\
468 \pm 49\end{array}$ & $\begin{array}{l}1.78 \pm 0.30 \\
2.89 \pm 0.22\end{array}$ & $\begin{aligned} 10.8 & \pm 1.6 \\
6.2 & \pm 0.8\end{aligned}$ \\
\hline
\end{tabular}


TABLE III

Effect of In Vivo or In Vitro Ethanol Administration on Ketone Metabolism in Rat Diaphragm

\begin{tabular}{cccc}
\hline Pretreatment & $\begin{array}{c}\text { Ethanol } \\
\text { in } \\
\text { medium }\end{array}$ & $\begin{array}{c}\text { Utilization of } \\
\text { acetoacetate }\end{array}$ & $\begin{array}{c}\text { Percent of } \\
\beta \text {-hydroxy- } \\
\text { butyrate-14C } \\
\text { converted } \\
\text { to }{ }^{14} \mathrm{CO}_{2}\end{array}$ \\
\hline Control diet & - & $304 \pm 18$ & $3.88 \pm 0.14$ \\
Ethanol diet & + & $307 \pm 19$ & $3.87 \pm 0.19$ \\
& - & $287 \pm 17$ & $3.42 \pm 0.13$ \\
of muscle per $\mathrm{hr}$ & $\%$ \\
\hline
\end{tabular}

Increased production of acetoacetate by the liver after alcohol pretreatment was paralleled by measurement of the conversion of palmitate- ${ }^{14} \mathrm{C}$ to acetoacetate ${ }^{14} \mathrm{C}$ : in the fed animals, alcohol pretreatment increased the percentage of the conversion from $0.54 \pm 0.06$ to 1.25 $\pm 0.13 \%(P<0.001)$, and, in the fasted rats, alcohol pretreatment increased this percentage from $1.78 \pm 0.30$ to $2.89 \pm 0.22(P<0.02)$.

As shown in Table II, although the alcohol effect was similar in the fed animals and in the fasted rats, all the values were higher in the latter. After pretreatment with the control diet, the blood acetoacetate concentrations were normal in the fed animals whereas they were significantly increased in the fasted rats.

Contrasting with the in vivo effects, addition of ethanol to the medium did not significantly modify either the production of acetoacetate by the liver or the conversion of labeled palmitate to acetoacetate $-{ }^{14} \mathrm{C}$.

Table II also indicates that the changes in hepatic glycogen concentration followed a trend opposite to that of ketone production. As expected, fasting decreased glycogen concentrations from $37.1 \pm 4.4 \mathrm{mg} / \mathrm{g}$ to $10.8 \pm 1.6$ in the rats pretreated with the control diet and from $20.2 \pm 5.0 \mathrm{mg} / \mathrm{g}$ to $6.2 \pm 0.8$ in the alcohol-pretreated rats. Alcohol pretreatment itself, however, significantly decreased the glycogen concentration in the postprandial state $(P<0.05)$ as well as in the fasting state $(P<$ $0.05)$; the combination of fasting and alcohol reduced glycogen concentrations to the very low level of $6.2 \pm 0.8$ $\mathrm{mg} / \mathrm{g}$.

In the group of rats who received only one gastric intubation of diet instead of 3 days of pretreatment, no significant differences of blood acetoacetate concentrations, acetoacetate productions in the liver slices, or hepatic glycogen concentrations were observed between the animals fed the control diet or those given ethanol.

As indicated in Table III, neither in vivo pretreatment with alcohol nor in vitro addition of alcohol had any significant effect upon the consumption of acetoacetate by rat diaphragm, although ethanol pretreatment of rats slightly but significantly decreased the percentage of $\beta$-hydroxybutyrate $-{ }^{14} \mathrm{C}$ converted to ${ }^{14} \mathrm{CO}_{2}$ from $3.88 \pm$ 0.14 to $3.42 \pm 0.13(P<0.001)$ and from $3.87 \pm 0.19$ to $3.42 \pm 0.14(P<0.02)$. In four incubations the addition of sodium acetate at a concentration of $10 \mu$ moles $/ \mathrm{ml}$ did not alter the acetoacetate consumption by diaphragm whether or not the animals were pretreated with ethanol. The acetoacetate consumption averaged 317 and 314 nmoles $/ 100 \mathrm{mg}$ of muscle per hour respectively with and without addition of acetate to diaphragms of control animals; the corresponding results in ethanol-pretreated rats were 284 and 294.

\section{DISCUSSION}

This study revealed that chronic administration of ethanol, in association with a calorically adequate fatcontaining diet, induces a marked hyperketonemia in man and in rats and that for an identical caloric and carbohydrate intake, ethanol is more ketogenic than isocaloric fat. Ethanol feeding also resulted in an increased production of ketones by rat liver slices.

Previous studies on the relation between ethanol and ketone metabolism yielded conflicting results. To assess the "anti-ketogenic" effect of alcohol, ethanol was given to both diabetic and "normal" subjects, in whom ketonuria was induced by fever or low carbohydrate diets; alcohol was found to decrease $(13,14)$, or not to affect (15) ketonuria. Most of these studies were of shprtterm duration (13) or involved rather nonspecific chemical assay methods. Ketonemia (16) after ethanol has also been noted, but five of the seven subjects were diabetic and ethanol was not given isocalorically. These various factors may explain the conflicting results obtained.

Clinically, ketonuria has been observed occasionally in acutely intoxicated alcoholic patients, and was generally attributed to poor nutrition or prolonged fasting (1). As shown clearly by our results, these conditions are not required. Even with an adequate intake of calories and protein, isocaloric substitution of carbohydrates or fat by ethanol produced a marked hyperketonemia and ketonuria, as long as the diet comprised a normal amount of fat.

The ethanol-fat diet contained only a minor proportion of carbohydrates ( $3 \%$ of total calories), and this factor, though of importance, is probably not sufficient by itself to account for the ketonemia, since a diet containing $4 \%$ of total calories as carbohydrates and $66 \%$ as alcohol, but with only $5 \%$ as fat, had no appreciable ketogenic effect. Furthermore, it has been observed that hyperketonemia produced by starvation in rats can be abolished or reduced by feeding fat in adequate caloric amounts (17). In man, except under maxi-

Effect of Ethanol on Ketone Metabolism 
mal starvation, a ketogenic diet furnishing over $92 \%$ of its calories in the form of fat and thus containing a low amount of carbohydrate may, if given early enough, delay or alleviate ketosis (18). Since our ketogenic regimen contained $15 \%$ of calories as protein, which are glucogenic, and $36 \%$ of fat (containing glycerol, also a precursor for gluconeogenesis), it would seem unlikely that lack of exogenous carbohydrate itself is the sole explanation for the ketotic effect observed with the ethanol diet. The key role played by alcohol is confirmed by our finding that a diet consisting of alcohol $(46 \%$ of calories) and fat (36\% of calories) is far more ketogenic than a high fat diet alone (82\% of total calories), though both had the same low carbohydrate content.

Theoretically, alcohol could induce the observed hyperketonemia and hyperketonuria by enhancing hepatic ketone production or reducing peripheral ketone utilization, or by a combination of both mechanisms. A reduction of peripheral utilization of ketones could result from elevated plasma acetate levels. However, acetate added to diaphragm incubations at a concentration of $10 \mu \mathrm{moles} / \mathrm{ml}$ did not alter acetoacetate consumption whether or not the animals were pretreated with alcohol. Crouse, Gerson, DeCarli, and Lieber (19) have demonstrated previously that ethanol feeding in man resulting in blood levels of ethanol as high as $110 \mathrm{mg} / 100$ $\mathrm{ml}$ resulted in a concentration of plasma acetate of only $1 \mu \mathrm{mole} / \mathrm{ml}$ which is 10 times less than the concentration used in our media. Blood ethanol concentrations in our patients varied but did not exceed $145 \mathrm{mg} / 100 \mathrm{ml}$ even on the $66 \%$ ethanol diet. Moreover when in the fasting state neither the patients nor the animals were metabolizing alcohol. This makes it unlikely that the ketonemia observed was secondary to a block of muscle utilization of ketones by acetate. Alcohol pretreatment in vivo induced a small decrease $(10 \%)$ of ${ }^{14} \mathrm{CO}_{2}$ production from labeled $\beta$-hydroxybutyrate in incubated diaphragms, but no decreased utilization of acetoacetate by the diaphragm was observed either under the influence of alcohol in vitro or after pretreatment of the rat with an alcohol-containing diet. To the extent that the diaphragm can be considered as representing the whole muscular mass, these experiments indicate that the accumulation of blood ketone results to a greater extent from increased hepatic production of ketones (observed in the liver slices) than from decreased utilization in muscle.

The biochemical mechanisms underlying hepatic ketogenesis are much debated $(20,21)$ and may vary in different "ketogenic" conditions. One probably can still accept the classic theory that the formation of ketones is regulated by the combination of $(a)$ an increased fat load upon the liver, through increased fat mobilization (fasting) or excessive fat intake (high fat-low carbohydrate diets), associated with $(b)$ a relative depletion of hepatic carbohydrate intermediaries necessary for the oxidation of fat through the citric acid cycle. These factors may ultimately result, as discussed by Bremer (22), in an increase of the ratio of acetyl-CoA over $\mathrm{CoA}$, which could be the determining factor regulating acetoacetate production.

Alcohol does not increase the intestinal absorption of fat (23) nor does it produce peripheral fat mobilization (24-26) except with very large amounts of ethanol in excess of those used in the present study $(23,27)$. In a previous study, chronic administration of amounts of ethanol similar to the ones fed in this study on a diet comparably restricted in carbohydrate, or with addition of $300 \mathrm{~g}$ of ethanol per day to an otherwise normal diet, did not elevate the fasting plasma concentration of free fatty acids (28). An increase of circulating free fatty acids was observed only when the oral intake of ethanol amounted to $400 \mathrm{~g} /$ day (28). The greatest daily dose of ethanol in our patients was $245 \mathrm{~g}$ in the single patient who consumed ethanol as $66 \%$ of calories. The hepatic metabolism of alcohol itself results in the production of two carbon fragments (29). This excess of acetyl radicals originating from ethanol, however, cannot suffice, by itself, to explain the excessive ketone production since a diet with a large amount of alcohol (but containing only $5 \%$ of fat as total calories) did not induce hyperketonemia. Moreover, most of the two-carbon fragments derived from ethanol are released from the liver as acetate (30), which, in turn, is predominantly metabolized in peripheral tissues (31). The fact that a diet containing $46 \%$ of ethanol and $36 \%$ of fat is more ketogenic than one containing $82 \%$ as fat also indicates that ethanol does not merely act as a source of twocarbon fragments. Alcohol has been shown to inhibit fatty acid and chylomicron oxidation $(10,32)$, probably through alteration of the citric acid cycle, possibly as a consequence of an altered redox potential induced by ethanol oxidation $(10,29)$. In addition, striking ultrastructural alterations of the mitochondria have been described after ethanol feeding (33-35); these may also affect mitochondrial function, especially fat oxidation. Alteration of lipid oxidation may indeed play an important role in explaining the ketogenic effects of ethanol in the postprandial state.

It must be pointed out, however, that the alcohol effect upon ketogenesis was predominant in the fasting state, when alcohol had disappeared from the blood and when its metabolic effects on the redox potential of the cells had already regressed, as indicated by the normal ratio between $\beta$-hydroxybutyrate and acetoacetate. The influence of ethanol on the metabolism of liver from fed and starved rats in liver perfusion experiments has been studied (36). The addition of ethanol to the perfusion media resulted in the almost complete cessation of $\mathrm{CO}_{2}$ 
production, the change being faster in the liver of the starved rats. The respiratory quotient of starved animals is known to be low (37). This is thought to be due in part to the oxidation of fatty acids to ketones, a process in which $\mathrm{O}_{2}$ is consumed without $\mathrm{CO}_{2}$ production. The more striking ketogenesis in our patients in the fasting state may reflect increased susceptibility in the fasting liver to some persistent effect of alcohol, including perhaps alterations in mitochondrial function associated with the marked ultrastructural changes (33, 35). Another explanation for increased ketone production during fasting was suggested by Bremer, who observed a decreased concentration of propionylcarnitine in the liver of fasting rats; this may in turn result in a decrease of propionyl CoA which is an inhibitor of acetoacetate-forming enzyme system (22).

Since oxaloacetate depletion has been considered to be one of the mechanisms responsible for ketone overproduction (17), it is of interest to note that acute administration of alcohol to rats did not modify the absolute amount of oxaloacetate, although it increased the ratio of malate over oxaloacetate (38). However, effects of chronic administration of ethanol on these parameters and, more specifically upon the mitochondrial oxaloacetate, are still unknown.

Conflicting results have been reported concerning the effects of intravenous ethanol on serum insulin. In one study, intravenous ethanol was not found to affect serum insulin (39), whereas in another report it produced hypoglycemia with a compensatory reduction of circulating insulin in fasting subjects (40). A reduction of serum insulin secondary to hypoglycemia could lead to increased ketogenesis. However, this is unlikely in our patients since ethanol was always given orally (and chronically) and repeated blood glucose levels were always normal.

In the rats, increased ketone production in liver slices occurred only after several days of ethanol pretreatment, and addition of ethanol in vitro was without effect. Similarly, splanchnic ketogenesis was unaffected when ethanol was given in acute experiments to volunteers (30). Thus the effect of ethanol on ketone metabolism is characterized by a delayed change which suggests that the alcohol effect may not result primarily from the presence of the ethanol and its immediate biochemical action, but rather from a progressive change in metabolic pathways in the liver, the nature of which has not been elucidated as yet. Our findings of a delayed effect of ethanol on ketone metabolism and the role of associated dietary factors, however, could tentatively be explained by the following hypothesis: the delay in the appearance of ketonemia after ethanol feeding may be due to the fact that time is required for the depletion of the glycogen stores in the liver. Glycogen depletion (which was verified in our animal experiments) most likely results from a combination of a low carbohydrate diet and an alcohol-induced block of gluconeogenesis (41). If dietary fatty acids are then given with the ethanol, their oxidation is probably impaired and ketogenesis markedly enhanced both because of the lack of carbohydrate and the ethanol-induced inhibition of the activity of the citric acid cycle. Much less ketonemia appears in the absence of ethanol, even with a high fat diet, probably because gluconeogenesis from glycerol and proteins can proceed normally under these conditions. Moreover, the difference in carbohydrate intake between the ethanol and high fat diets (due to the glyceride-glycerol), though small, could contribute to higher hepatic glycogen levels. Less ketonemia also appeared with a high dose of ethanol alone (in the virtual absence of dietary fat) because the two-carbon fragments derived from ethanol are exported from the liver as acetate (which is utilized primarily in peripheral tissues) (31) instead of being converted to ketone bodies in the liver, as is the case for fatty acids.

\section{ACKNOWLEDGMENTS}

We wish to thank the Misses L. M. DeCarli, N. Lohse, C. Ryavec, and B. Smol for their expert technical assistance.

This study was supported, in part, by U. S. Public Health Service Grants AM 12511 and MH 15558 and Fellowships MH 40, 880 (Dr. Lefèvre) and AM 32629 (Dr. Adler).

\section{REFERENCES}

1. Dillon, E. S., W. W. Dyer, and L. S. Smello. 1940. Ketone acidosis in non-diabetic adults. Med. Clin. $N$. Amer. 24: 1813.

2. Food and Nutrition Board, Recommended Dietary A1lowances. Publication 1146. 6th revised edition. Washington, D. C. 1964. National Academy of Sciences National Research Council.

3. Weichselbaum, T. E., and M. Somogyi. 1941. A method for the determination of small amounts of ketone bodies. J. Biol. Chem. 140: 5.

4. Walker, P. G. 1954. A colorimetric method for estimation of acetoacetate. Biochem. J. 58: 699.

5. Michaels, G. D., S. Margen, G. Liebert, and L. W. Kinsell. 1951. Studies in fat metabolism. The colorimetric determination of ketone bodies in biological fluids. $J$. Clin. Invest. 30: 1483.

6. Bonnichsen, R. 1963. Ethanol-determination with alcohol dehydrogenase and DPN. In Methods of Enzymatic Analysis. Hans-Ulrich Bergmeyer, editor. Academic Press Inc., New York. 285.

7. DeCarli, L. M., and C. S. Lieber. 1967. Fatty liver in the rat after prolonged intake of ethanol with a nutritionally adequate new liquid diet. J. Nutr. $91: 331$.

8. Beatty, C. H., A. Marcó, R. D. Peterson, R. M. Bocek, and E. S. West. 1960. Acetoacetic acid metabolism by skeletal muscle fibers from control and diuretic rats. J. Biol. Chem. 235: 2774.

9. Passman, J. M., N. S. Radin, J. A. D. Cooper. 1956. Liquid scintillation technique for measuring carbon-14dioxide activity. Anal. Chem. 28: 484. 
10. Lieber, C. S., and R. Schmid. 1961. The effect of ethanol on fatty acid metabolism; stimulation of hepatic fatty acid synthesis in vitro. J. Clin. Invest. 40: 394.

11. Jones, J. A., and M. Blecher. 1965. On the mechanism of $\beta$-oxidation of long chain fatty acids by liver mitochondria from normal and alloxan-diabetic rats. J. Biol. Chem. 240: 68.

12. Hassid, W. Z., and S. Abraham. 1963. Chemical procedures for analysis of polysaccharides. In Methods in Enzymology. S. P. Colowick and N. O. Kaplan, editors. Academic Press Inc., New York. 3: 34.

13. Benedict, H., and B. Torök. 1906. Der Alkohol in der Ernährung der Zuckerkranken. Z. Klin. Med. 60: 329.

14. Staubli, C. 1908. Beitrage zur Pathologie und Therapie des diabetes mellitus. Deut. Arch. Klin. Med. 93: 107.

15. Higgins, H. C., F. W. Peabody, and R Fritz. 1916. A study of acidosis in three normal subjects, with incidental observations on the action of alcohol as an antiketogenic agent. J. Med. Res. 34: 263.

16. Schlierf, G., B. Gunning, H. Uzawa, and L. W. Kinsell. 1964. The effects of calorically equivalent amounts of ethanol and dry wine on plasma lipids, ketones, and blood sugar in diabetic and non-diabetic subjects. Amer. J. Clin. Nutr. 15: 85.

17. Mayes, P. A. 1962. A calorie deficiency hypothesis of ketogenesis. Metabolism (Clin. Exp.). 11: 781.

18. Freund, G. 1965. The calorie deficiency hypothesis of ketogenesis tested in man. Metabolism (Clin. Exp.) 14: 985.

19. Crouse, J. R., C. D. Gerson, L. M. DeCarli, and C. S. Lieber. 1968. Role of acetate in the reduction of plasma free fatty acids produced by ethanol in man. J. Lipid Res. 9: 509.

20. Johnson, R. E., R. Passmore, and F. Sargent. 1961. Multiple factors in experimental human ketosis. Arch. Intern. Med. 107 : 111.

21. Williamson, D. H., M. W. Bates, and H. A. Krebs. 1968. Activity and intracellular distribution of enzymes of ketone-body metabolism in rat liver. Biochem. J. 108: 353.

22. Bremer, J. 1969. Pathogenesis of ketonemia. Scand. J. Clin. Lab. Invest. 23: 105.

23. Lieber, C. S., N. Spritz, and L. M. DeCarli. 1966. Role of dietary, adipose, and endogenously synthesized fatty acids in the pathogenesis of the alcoholic fatty liver. J. Clin. Invest. $45: 51$.

24. Lieber, C. S., and N. Spritz. 1966. Effects of prolonged ethanol intake in man: role of dietary, adipose, and endogenously synthesized fatty acids in the pathogenesis of the alcoholic fatty liver. J. Clin. Invest. 45: 1400.

25. Jones, D. P., E. Perman, and C. S. Lieber. 1965. Free fatty acid turnover and triglyceride metabolism after ethanol ingestion in man. J. Lab. Clin. Med. 66: 804.
26. Feinman, L., and C. S. Lieber. 1967. The effect of ethanol on plasma glycerol in man. Amer. J. Clin. Nutr. 20: 400 .

27. Brodie, B. B., W. M. Butler, Jr., M. G. Horning, R. P. Maickel, and H. M. Maling. 1961. Alcohol induced triglyceride deposition in liver through derangement of fat transport. Amer. J. Clin. Nutr. 9: 432.

28. Lieber, C. S., D. P. Jones, J. Mendelson, and L. M. DeCarli. 1963. Fatty liver, hyperlipemia, and hyperuricemia, produced by prolonged alcohol consumption, despite adequate dietary intake. Trans. Ass. Amer. Physicians (Philadelphia) . 76: 289.

29. Lieber, C. S. 1968. Metabolic effects produced by alcohol in the liver and other tissues. Advan. Intern. Med. 14: 151 .

30. Lundquist, F., N. Tygstrup, K. Winkler, K. Mellemgaard, and S. Munck-Petersen. 1962. Ethanol metabolism and production of free acetate in the human liver. $J$. Clin. Invest. 41: 955

31. Katz, J., and I. L. Chaikoff. 1955. Synthesis via the krebs cycle in the utilization of acetate by rat liver slices. Biochim. Biophys. Acta. 18: 87.

32. Lieber, C. S., A. Lefèvre, N. Spritz, L. Feinman, and L. M. DeCarli. 1967. Difference in hepatic metabolism of long- and medium-chain fatty acids: the role of fatty acid chain length in the production of the alcoholic fatty liver. J. Clin. Invest. 46: 1451.

33. Iseri, O. A., C. S. Lieber, and L. S. Gottlieb. 1966. The ultrastructure of fatty liver induced by prolonged alcohol intake. Amer. J. Pathol. 48: 535.

34. Lane, B. P., and C. S. Lieber. 1966. Ultrastructural alterations in human hepatocytes following ingestion of ethanol with adequate diets. Amer. J. Pathol. 49: 593.

35. Lieber, C. S., and E. Rubin. 1968. Alcoholic fatty liver in man on a high protein-low fat diet. Amer. J. Med. 44: 200.

36. Forsander, O. A., N. Räihä, M. Salaspuro, and P. Mäenpää. 1965. Influence of ethanol on the liver metabolism of fed and starved rats. Biochem. J. 94: 259.

37. Blixenkrone-M $\varnothing 1$ ler, N. 1938. Respiratorischer Stoffwechsel und Ketonbildung der Leber. Hoppe-Seyler's Z. Physiol. Chem. 252: 117.

38. Rawat, A. K. 1968. Effects of ethanol infusion on the redox state and metabolic levels in rat liver in vivo. Eur. J. Biochem. 6: 585.

39. Abramson, E. A., and R. A. Arky. 1968. Acute antilipolytic effects of ethyl alcohol, and acetate in man. J. Lab. Clin. Med. 72: 105.

40. Bagdade, J. D., E. L. Bierman, and D. Porter, Jr. 1969. Counter regulation of basal insulin secretion during alcohol hypoglycemia in diabetic and normal subjects. Diabetes. 18: 323

41. Freinkel, N., and R. A. Arky. 1966. Effects of alcohol on carbohydrate metabolism in man. Psychosom. Med. 28: 551 . 